\title{
Framing regeneration: Embracing the inhabitants
}

Corresponding Author:

Menna Tudwal Jones, Business School, University of Greenwich, Greenwich Campus, Old Royal Naval College, Park Row, London SE10 9LS.

\begin{abstract}
Cities are central to neoliberalism and therefore, there is a need to understand the tools used by policy makers to present and garner support from inhabitants to this ideology. By understanding how policy makers encourage inhabitants to support the attraction of private investment, it will be possible to recognise how power is manifested at a local level. This article proposes to demonstrate how the Local Authority and other public and private (and publicprivate partnership) organisations in Liverpool intend to embrace the inhabitants in urban neoliberal policies. Such recognition gives insight on how the process of urban neoliberalism has evolved and is advocated at a local level. By means of frame analysis (Goffman E (1986) Frame Analysis: An Essay on the Organization of Experience. Boston, MA: Northeastern University Press) of strategic documents, it is proposed that the inhabitants are stereotyped according to specific characterisations and hence, included within the narratives of urban regeneration as a 'product'. It is argued that this commodification and one-dimensional image of the inhabitants becomes a means of giving a global representation through the reappropriation of historical stereotypes. The paper demonstrates how future success is constructed, with neoliberalism legitimated through imposition and control of the inhabitants' identity.
\end{abstract}

Keywords Capital of Culture, local communities, neoliberalism, place identity, urban regeneration

\section{Introduction}

This article demonstrates how a neoliberal agenda evolves. It is argued that whilst there is space given to including the social components of place - ideas around the identity and image of inhabitants and communities - this representation is a means of securing 'order and control amongst marginalized populations' (Peck et al., 2009 : 58). As place marketing is utilised in neoliberal policies to attract investment and jobs (Peck et al., 2009: 58), through the analysis, one of the techniques utilised by policy makers in urban neoliberalism governance can be understood. By focusing on certain characteristics, positive stereotypes of the inhabitants are built. Referred to in the findings section as 'natural characteristics', these intangible attributes 
prescribe the range of acceptable behaviours that can be expressed. As such, what this indicates is that only by following such controlled behaviour can the inhabitants feel any hope of success, by 'do[ing] their bit for market-led regeneration' (Holden and Iveson, 2003: 67).

The importance of the locality and culture in persuading the inhabitants to support urban regeneration initiatives is recognised by Kavaratzis and Ashworth (2015) in their work on place branding. Recognition of the 'community' within urban regeneration initiatives has, however, existed for some time: Cox and Mair (1988) noted how community was presented in place marketing through propaganda around 'the status of the locality' (p. 320), employed to gain consensus on urban regeneration strategies. This need for consent from the inhabitants continued in third way politics to legitimise neoliberalism. Philo and Kearns (1993) termed this 'socialisation', a means of winning over local people to support competition around 'selling places'. Such 'softer issues of community' (Tallon, 2013) became prominent from the late 1990s/early 2000s because of changes in how impacts of urban regeneration were discussed both locally and nationally (Smith and Fox, 2007) with an apparent 'concern' for the inhabitants' welfare.

The case study, Liverpool European Capital of Culture 2008 (ECoC08), adheres to New Labour's neoliberal approach to urban regeneration (Fuller and Geddes, 2008). Although the data relates to 2008, as a neoliberal agenda continues to develop, and the literature review includes contemporary references relating to issues around the understanding of 'community', the findings can still be deemed relevant. Not only are the findings relevant, but they reveal how urban neoliberalism has been able to evolve, and appear credible, whilst as the literature review and the findings section show, being questioned academically. A key driver for economic growth was competition, linked to continual statements about 'community empowerment' (Jones, 2010). Indeed, Richard Rogers' urban renaissance vision recommended that: 'citizens must be involved in the evolution of their cities' (quoted in Holden and Iveson, 2003: 58). Such an approach is evident in central government policy, for example, in the Communities and Local Government (2009) advice, that a combination of personal history, characteristics, and perceptions that bring about interaction with other people and place are deemed important for identity formation and a 'sense of belonging'. Belief that transforming the representation of place is for 'a common good' could also be found in the Office of the Deputy Prime Minister (ODPM, 2004: 8) report, where it explains how a 'Comprehensive Performance Assessment' framework would be used by all eight cities ${ }^{1}$ to 'help them deliver the quality services that our communities demand'.

I will begin by discussing literature on how inhabitants are incorporated into urban regeneration projects. The methods section will clarify how the research was carried out using ECoC08 as a case study. Findings are separated into three sub-sections relating to how the inhabitants are incorporated into urban regeneration narratives to endorse a neoliberal agenda, followed by a conclusion. 


\section{Literature review}

There is recognition of how inhabitants are mentioned within urban regeneration narratives, with local identities incorporated into urban neoliberal policies. Therefore, although 'inhabitants' and/or 'community' are identified, there is a need to analyse how they are deemed a competitive advantage and utilised to justify and legitimise a neoliberal agenda.

From a place branding perspective, community is presented through a one-dimensional image of local culture, which is thus defined, and imposed on the inhabitants (Kavaratzis and Ashworth, 2015). Such a simplistic image essentially has always needed to be consistent with business needs (Cox and Mair, 1988: 314):

the local community is presented as a caring community, a producer of brave men, of great men and women, of ideas and inventions. This image suggests, and is intended to suggest that the local community is worth defending and safeguarding.

As Madureira and Baeten (2016) note, promotion is based on those that are 'deemed fit for the city' (p. 363) rather than on the actual residents. Such representation needs to be questioned, particularly as it only promotes 'cities imagined, cities dreamed' (Dinardi, 2017: 95). For the 'actual' inhabitants, however, there is persuasion in the representation given, because of the process of 'socialisation' (Philo and Kearns, 1993: 3) by which local people (especially the poor) become convinced that regeneration is best for their community and for their own good as 'all sorts of "good things" are really being done on their behalf'. How the inhabitants are represented thus needs to be analysed for its warped anticipation, and how it is utilised as a means of justifying the development of a neoliberal agenda.

Enhancing images of place in this manner can be defined as 'selective story telling' (Vanolo, 2015: 2), which includes optimistic images and representations. The positive depiction of place presented by Local Authoties ${ }^{2}$ (LAs) and entrepreneurs utilises history as a source of pride and inspiration for the present during the aforementioned process of 'socialisation' (Philo and Kearns, 1993). Boyle (1997) furthers the understanding of 'socialisation', using Glasgow's position as 1990 City of Culture ${ }^{3}$ as a case study, explaining how the event (termed an 'Urban Propaganda Project' - UPP) was utilised to illustrate the progress made in regeneration (what Snow and Benford, 1988, describe as a means of generating motivation). Consequently, the civic boosterism of UPPs propagates 'solutions that legitimate the principles of capitalism and free market competition for investment' (Boyle, 1997: 1983). There is a belief, however, that by coordinating the 'core-attributes and values between the place and the self' (Zenker et al., 2017: 18) the inhabitants can identify with place and the urban regeneration narratives presented. Only if such multifaceted association in urban regeneration occurs can the process be deemed democratic and legitimate (Eshuis and Edwards, 2013).

To legitimise and obtain policy support, Lawrence et al. (2010) demonstrate that when target groups are discussed positively, the issue is encouraged. Even the 'urban poor' are discussed in policies 'as crucial contributors to inclusive cities' (Beall, 2000: 843). Massey (1993) 
recognises that an emotional involvement with the inhabitants is achieved through focusing on local 'identities' and 'pride'. She argues that the construction of 'place' is developed by reference to the 'historically' iconic, which has the potential to connect individuals with both place and the power relations that exist between political, cultural and social domains. Examples from history, albeit tangible ones, are given by Berglund (2011), when arguing how historic visual records are utilised as resources to justify transformation of the built environment, noting that 'participation has turned into persuasion' (p. 15), and that 'paternalistic injunction' (p. 14) is employed to influence the inhabitants. Kavaratzis and Ashworth (2015) demonstrate the process by which culture is utilised in order to "persuade locals' to support regeneration initiatives. Similarly, analysis on the manipulative role of representation to legitimise certain narratives has been documented by Said (2000). Likewise, Bourdieu (1977) acknowledges how those in power impose and legitimise meaning through 'symbolic violence'.

Although the need to secure power through 'order and control amongst marginalised populations' is discussed by Peck et al. (2009: 58), how those 'marginalised populations' are intentionally represented in such policies in order to support urban neoliberal initiatives is not revealed. Particular instances are given on how a place's image is controlled: Avraham (2014) explains how problematic characteristics become an asset as they 'convert [from] negative to positive' (p. 176); the examples given are all tangible, whereas the ones discussed in this paper relate to intangible characteristics and stereotypes. The impact of such representation, however, is realised by Kavaratzis and Ashworth (2015: 166): '... places become trapped in single episodes of their long history and particular expressions of their diverse local culture at the expense of all the rest'.

This literature review has focused on the inhabitants; however, the requirement for partnership in the regeneration process necessitates the inclusion and motivation of an array of organisations, decision-makers and the public (Davies, 2003). Davies underlines the difficulty for LAs as central government pressurises them to produce a logical shared action in such complex circumstances. Snow and Benford (1988) associate this need for consensus with the production of 'corrective action' that acts as an impetus for agreement in motivational framing by taking responsibility for and, simultaneously, giving meaning to experiences. Thus, the culture of place: 'how space is filled up by people, practices, objects and representations' (Gieryn, 2000: 465) becomes an important means of gaining involvement and consensus (Sepe, 2014). Incorporating large-scale cultural events for urban regeneration attends to numerous requirements: it gives shared experiences and is a 'tool of neoliberal governance through the conjunction of business, play and fantasy' (Waitt, 2008: 513; see also Boyle's, 1997, aforementioned UPP argument). Thus, to understand how consensus from the inhabitants is generated at a time when 'hard' and 'soft' factors are brought together (what Giovanardi, 2012, terms 'haft' and 'sord') that focus on neoliberalism (MacLeavy, 2008), there is a need to examine how such narratives are employed at a local level, which this research article demonstrates. 


\section{Methods}

To investigate how support for a neoliberalist agenda is achieved at a local level, Liverpool's status as ECoC08 is utilised as a case study. Policy and strategic urban regeneration documents written in the years leading up to and including 2008 are analysed using frame analysis (Goffman, 1986), specifically applying Snow and Benford's (1988) 'motivational framing'.

\section{The case study}

The case study approach provides a means of studying how inhabitants are represented and encouraged to support urban neoliberalism. The case study is a method for understanding complicated social occurrences, as it 'allows investigators to retain the holistic and meaningful characteristics of real-life events' (Yin, 2003: 2). A single city (Liverpool) was used for an appreciation of the 'local' in this case study. Liverpool is a city in the North West of England with a population of 454,500 in 2008 (www.liverpool.gov.uk). Situated within the county of Merseyside, and together with the LAs of Halton, Knowsley, St Helens, Sefton and the Wirral, it constitutes the 'Liverpool City Region' (www.liverpoollep.org).

The case study - Liverpool ECoC08 - is an exemplar of contemporary 'culture-led' (Evans, 2001), or 'event-led' (Smith and Fox, 2007), forms of post-industrial (or in this case, a redundant dockland ${ }^{4}$ ) regeneration. The case study demonstrates how neoliberalism attempts to transform problem places into 'festival places' (Waitt, 2008). An Urban Regeneration Company managed ECoC08 by coordinating the LA, a regional development agency and private sector representation. Two of the four objectives in the Liverpool City Council bid document were regeneration led: 'Developing a positive profile and image of the city in the region, Europe and internationally', and 'increasing the confidence and pride of its citizens' (Liverpool Culture Company, 2003: 301). Liverpool has what Theodore and Peck (2011: 25) would describe as a 'positive momentum' towards neoliberal policies; however, regeneration in the city is predominantly supported by national and European funding (Rink et al., 2012).

Support from organisations and the public acquired a new meaning by June 2003, following an official visit by the judging panel. One of the quotations given in the press was from a Department of Culture, Media and Sport report where the Chairman of the Advisory Panel, describes Liverpool as: 'a city whose people are wholly and enthusiastically committed to a year of culture in 2008' (Isaacs, 2003: 7). In the recommendations, public support for successful urban regeneration is highlighted: 'Liverpool's bid, crucially, best combines strong central direction, civic leadership with wholehearted public participation' (Isaacs, 2003: 7).

\section{Documentary analysis}

Documentary analysis was used to provide a measurable way of determining how certain qualities of Liverpool's inhabitants were mobilised. Publications written around the time of the case study were examined as this demonstrated 'how the specific issues it [the rhetorical work of the text] raises are structured and organized and chiefly how it seeks to persuade you about 
the authority of its understanding of the issue' (Rapley, 2007: 113, emphasis in the original). Business material aimed at policy advisers and for general dissemination, and promotional material that specifically targeted the business investor/tourist were analysed. The material was identified through a mapping exercise of promotional bodies that had a direct role in shaping Liverpool's regeneration agenda. These included: Culture Company, ${ }^{5}$ City Council, Liverpool's Business Improvement District and Liverpool Vision, ${ }^{6}$ Liverpool First (their role was in partnering public, private, voluntary and community agencies, see www.liverpoolfirst.org.uk/who-we-are), The Mersey Partnership ${ }^{7}$ and the North West Development Agency ${ }^{8}$ (NWDA). There was no overall sampling of the documents, instead all relating to business and tourism investment were analysed, as they presented an intentional representation of the city and its inhabitants.

\section{Frame analysis}

Frame analysis was used to analyse how the inhabitants' support was gained for the regeneration initiative. It originates from Goffman's (1986) work, where he describes how individuals negotiate their behaviour and how the perspectives through which people understand the world are shaped. To supplement Goffman's (1986) instruction, Gamson's (1992) research into how people make sense of politics was also referred to as it explained the process undertaken to code the frames. To indicate that frame analysis can also be carried out on written material, Strom and Cook's (2004) analysis of transcripts of debates held in congress and articles from the New York Times was useful.

In addition to appreciating how frame analysis has been employed for research, it is also worth understanding how Goffman's (1986) concept has been developed. Snow and Benford (1988) explain how support for certain actions is fostered through consensus and action mobilisation as frame analysis involves three core framing tasks, which direct agreement and generate appropriate action. These tasks are:

- Diagnostic framing: identification of a problem and recognition, or blaming, of the cause.

- Prognostic framing: proposed solution to the diagnosed problem, it entails strategies, tactics and targets.

- Motivational framing: summons support for involvement, by rationalising the need for reform or 'corrective action'.

The third core-framing task has been applied to the data, as it focuses on how the inhabitants are summoned to support and feel involved in the regeneration movement (ECoC08). Analysis using diagnostic and prognostic framing is not required, as it does not demonstrate how an appeal is made to the public.

Frames were identified from reading the documents, with a list made of how the inhabitants were represented. Frames were devised from re-reading the list and identifying how the inhabitants were attributed (the frames). Frames were recognised from what was emphasised 
from the perspective of the locality - how the community/inhabitants are incorporated into the regeneration discourse. Analysis centred on how strong an implication was presented to the idea of the inhabitants being a part of the neoliberal agenda. Coding of these frames for this article were on three specific aspects/variations: 'The friendliness of the inhabitants': 'The workforce' and 'The inhabitants' diversity'. Variations of the frame emphasise a particular understanding of the inhabitants: giving them a role in urban regeneration, it legitimises a certain action and regards them as a tool in the regeneration policy. Re-occurrence of the frames could be noted in numerous ways depending on the type of document and the intended audience. The frame provides detail on how there is an opportunity for urban regeneration in Liverpool to succeed as a result of the inhabitants, attributes, which could thus be recognised as what Snow and Benford (1988) would term 'prods to actions' found in motivational framing. The data were only analysed if there was a connection between mentioning the inhabitants and how they can be a part of urban regeneration. General expressions about the city have not been analysed, as they do not contextualise involving the inhabitants.

\section{Findings}

Analysis of documents relating to Liverpool's regeneration for the years up to, and including, 2008 demonstrates how the inhabitants are calculated into the formula of the city's future success. Holden and Iveson (2003: 62) identify how individuals and communities are regulated in the 'routinization of neo-liberalism'. Likewise, Theodore and Peck (2011) demonstrate how 'regularized commonsense' (p. 37) is conveyed in the evolution of urban neoliberalism. Here, the inhabitants are deemed to have opportunities through urban regeneration, if they behave responsibly. Acknowledging the inhabitants' importance and their beneficent characteristics takes several different forms; collectively these function to give them a purpose in the regeneration initiative and to ensure consensus. The key beneficial attributes of the inhabitants, for Liverpool's regenerationv will be discussed below and all emphasise the intangible.

\section{The friendliness of the inhabitants}

In claiming that the natural characteristic of the inhabitants is friendliness, a favourable stereotype becomes a quality, which in the literature gives the city a competitive edge. Indeed, Liverpool First go as far as advising that the competitive advantage as an international city [is] through the people of Liverpool, the creativity, wit, energy and uniqueness of our communities' (Liverpool First, 2008: n.p.) It is these qualities that are also discussed, and in more detail, in other documents. In the ECoCO8 Vision Document, the city and its inhabitants are described as:

Liverpool's identity is unique - an edgy city, sometimes disrespectful and sometimes irreverent, famed for

- the character of its people - their wit, chat, story telling, friendliness and opinions; 
- it's [sic] extraordinary artistic creativity - performance, writing, new media, film and comedy and its eclectic mix of cultural organisations;

- it's architecture - its World Heritage status;

- it's maritime and industrial heritage and significance - one of the worlds [sic] former major ports - influencing the city's tendency to look outwards to the west rather than inwards to the rest of the country;

- it's diverse communities;

- $\quad$ it's sporting passions; and

- it's musical vibrancy. (Liverpool Culture Company, 2006: 2)

These qualities of the city's population are supplemented by well-known stereotypes: 'character[istics] of its people', involving qualities such as 'wit, chat, story telling, friendliness and opinions'. This implies a need to appeal to the inhabitants themselves and produce pride through compliments. Boyle's (1997) analysis of how UPPs construct local identities to a global audience can be recognised here, as familiar stereotypes and international recognition in architecture, maritime position, sport and music are boosted as acknowledged attributes. Capitalising on such positive characteristics to compliment the inhabitants exploits their identity (or a part of it at least) to generate support, which can cause tension (Kavaratzis and Ashworth, 2015) with the population it is meant to entice.

The inhabitants' identity becomes central owing to the positive generalisations that are recognised as fundamental characteristics. These characteristics give the sense of inclusion in the transformation of the city. Their historical circumstance that has 'influenced the city's tendency to look outwards' becomes a credential that can be recommenced following years of economic hardship and disinvestment. Hence looking outwards becomes a means of supporting a move away from state intervention, to desiring a neoliberal agenda for socioeconomic development. Although the looking 'outwards' is based on the historical rather than the future, what Kavaratzis and Ashworth (2015) recognise as a means of entrapment in the past is here utilised as a means forward. The incorporation of 'heritage narratives' is paramount, as 'persuasion is not likely to occur unless an audience is already positioned to be receptive to particular appeals' (Bridger, 1996: 355).

Appealing to the inhabitants by listing personal and personable characteristics that can be employed for promoting the city constructs them as a valuable commodity. Finding a function for the stereotypes (positive and negative) that are held of the city and its inhabitants demonstrates the desperate need (in that nothing is left out) to include everything about the city as a unique selling point for gaining investment. Murray (2001) argues that generally place is not recognised in its complexity when promoted; by giving a list of 'unique' positive and negative identity characteristics, an attempt is made to reveal a basic (and complimentary) understanding of the complexity of identity. It gives what Zenker et al. (2017) would argue is 
a means of incorporating an 'identification target' (p. 17). However, the characteristics made known lack the depth expected of interconnecting elements needed to understand identity.

Linking the inhabitants' characteristics with opportunities for investment implies their inclusion in the economic relations of the city, as it is their attributes that will generate investment. Massey (1993: 65) holds that if 'people have multiple identities, then the same point can be made in relation to places' with no necessary connection between them. Therefore, by linking and including the inhabitants in the city's investment opportunities, an attempt is made to connect them to economic development to guarantee support. Additionally, according to Snow and Benford (1988: 199), 'movements must drum up support' through specific tasks in order to ensure a shared, consensual aim. Garnering encouragement for ECoC08 entailed capitalising on well-known local characteristics for a unique selling point, although the difficulty for smaller cities to utilise their unique softer attributes for a global market is immense (Kaufmann and Arnold, 2018).

Whilst in some documents a positive characterisation of Liverpool's inhabitants exists, in other documents, aspects of Liverpool's 'character' have potential, if improved. For example, in the Winning Tourism strategic document, items in a superficial list of stereotypical characteristics are recognised as requiring further development for successful urban regeneration:

Liverpool is a highly creative city with huge human capital potential that can be used to give it a competitive edge. The Liverpool Culture Company can take a lead in this respect in preparing the city for the large influx of visitors that the City Region will attract as a Capital of Culture. A concerted campaign to improve the Liverpool Welcome in all its facets is required building on the unique warmth and humour of local people ... (The Mersey Partnership, 2003: 16, emphasis in original)

What can be noted here again is the use of a specific one-dimensional characterisation of the inhabitants; what is deemed to be natural ('the warmth and humour of local people') is affected to impress visitors and becomes required, or 'suitable', behaviour that has an economic value. Thus suitable and safe stereotypes can be employed to 'sell' Liverpool, whilst at the same time providing pride in and for the inhabitants. The appropriated and cautiously chosen characteristics have been refined and developed for presentation as important qualities.

Such appropriation means the inhabitants are recognised for their 'human capital potential', what Philo and Kearns (1993) describe as the 'socialisation' process, becoming 'important cogs' in regeneration. It is through their 'potential', which incorporates their natural (and 'unique') 'warmth and humour', that improvements can be made. Similarly, in another document, 'capitalising on the natural friendliness of local residents to offer sparking customer service' is a priority (The Mersey Partnership, n.d.: 10). Focusing and developing the 'warmth and humour' can make it a useful commodity. However, if local people's 'warmth and humour' is not improved, 'Liverpool Welcome' will not be satisfactory and a competitive edge cannot be ensured. The approach taken to guarantee support follows Snow and Benford's (1988) 'corrective action' - the effort made focuses on cooperation; it attempts to demonstrate 
satisfaction and present pride in the effectiveness to date, in regenerating Liverpool. The effectiveness of the regeneration is portrayed in terms of 'pride in the action taken', or in terms of promoting the already established positive characteristics of the inhabitants - 'selective incentives' (Snow and Benford, 1988: 202).

Pride in having such 'warmth and humour' generates motivation among the local population for the chosen approach in regenerating Liverpool. Based on their qualities, a high opinion is created, producing enthusiasm for the 'Liverpool Welcome' initiative. Promoting certain positive characteristics commodifies identity in a similar way to what Cox and Mair (1988: 317) recognise in the policies of local business coalitions (in the USA) as recasting 'concepts of local community in a form that better suits their needs'. As a part of this process, the local community (in Liverpool) is presented with a homogenous, dependable image that, once improved, will appeal to potential investors. It is propositioned, however, that following a neoliberal agenda will be easy for the inhabitants, as the city is 'creative', which implies adaptability and an ability to imagine the opportunities available from tourism investment.

What the examples given above demonstrate is how natural, intangible characteristics are controlled and then employed in urban regeneration narratives to draw in potential investors. However, to gain investment, simplified, manageable stereotypes of the inhabitants' identities are created.

\section{The workforce}

Stereotyping behaviour is linked to another aspect of urban regeneration: job creation. For example, the Winning Tourism strategic document explains how:

The City Region is widely recognised for its creativity both in terms of new businesses and employment opportunities, its vibrant, multi-cultural feel and its innovative approach to city centre management and destination creation. The raw, creative talent of the people of the City Region has been harnessed to provide a high quality level of customer service delivered with a flair and style that is uniquely 'Liverpool'. (The Mersey Partnership, 2003: 5)

Similar to the manner in which friendliness was presented as a natural attribute, the characteristics of 'the people of the City Region' - with their 'raw, creative talent' - are 'widely recognised'. This recognition acts as a 'prod to action' (Snow and Benford, 1988: 202) by demonstrating how the job creation approach to regeneration will be easy, as the inhabitants' talents are well known, and that the 'customer services' delivered will be acknowledged as being unique. Thus, once again, while certain characteristics of the inhabitants are acknowledged it is only within a limited, one-dimensional, set of parameters. This one dimension 'has been harnessed', which not only means that it has been exploited as a 'customer service' that can be delivered to tourists, it also indicates how individual characteristics are to be controlled for the potential and useful benefit of visitors. In this sense, the inhabitants become a tool that should 'do their bit for market-led regeneration' (Holden and Iveson, 2003: 522). Neoliberalism is legitimated as it gives the inhabitants an opportunity to behave 
responsibly (Swyngedouw, 2011) by demonstrating their uniqueness, thus competitively setting Liverpool apart.

Manipulation of the inhabitants into an image is recognisable from portraying the 'raw, creative talent'; the implication is that rawness needs to be treated and controlled to be beneficial. Inhabitants can only be of benefit to the local economy if they conserve their 'talent' for a 'uniquely 'Liverpool' service, an analysis that fits closely with what Cox and Mair (1988) describe as the promotion of local communities as being 'worth defending and safeguarding' (p. 317), which should 'mobilise civic pride and the sense of belonging' (Braun et al., 2013: 23). By being 'creative', the inhabitants can contribute to the regeneration process by assisting the 'City Region' in being inventive in how uniqueness is presented in order to competitively gain investment. Although to conserve talent implies protecting it from change, the need to 'harness' such talent diverges from protection to giving it a greater value: benefiting customer service. Here, how policy makers encourage the inhabitants to commit to economic regeneration is indicated. The need to engage with the community is similarly acknowledged by MacLeavy (2008: 1664), where the local authority (in Bristol's New Deal for Communities scheme) proposed 'to raise levels of economic activity by instating active citizen-subjects to work together to win government funds, attract private investment and encourage local enterprise'.

Although recognising that 'Businesses choose Liverpool for many reasons' (Liverpool Vision, n.d.: n.p.) in order to attract and support investment, one of the perceived incentives is the 'skilled workforce' (Liverpool Vision, n.d.: n.p.) Further detail on developing the workforce is given in the Merseyside Economic Review 2006 Summary. Attention is aimed at altering and improving the workplace and its workforce.

Jaguar's Halewood ${ }^{9}$ plant manufactures the luxury X-TYPE and employs approximately 2,200 people. In 2000, a significant investment transformed the Halewood plant from a massproduction operation assembling the Ford Escort to a world class manufacturing facility capable of producing the award winning Jaguar X-TYPE. This was complemented by a culture change strategy and a million hour training programme, which ensured Halewood's people and processes were ready to build a luxury vehicle ... (The Mersey Partnership, n.d: n.p.)

The Fordist history of the plant, as somewhere that mass-produced what could be regarded as an ordinary and familiar car of the Fordist era - the Ford Escort - is discussed in contrast to the new way of working. This change entailed staff sustaining 'a million hour training programme' to 'build a luxury vehicle' which fits with ideas of post-Fordism. Although, in reality, how a car is produced had not changed significantly from the Fordist era of massproduction (neither was the Jaguar X-TYPE individually produced - see www.jaguarlandrover.com), what is important is to seem in opposition to that era.

Post-Fordism is defined as a new phase of capitalist development, resulting in the end of massproduction. Discussing the transition from assembling Ford Escorts to a 'Post-Fordist' assemblage of the Jaguar X-TYPE reveals Liverpool's transformation to 'very different 
economic societal and political norms' (Amin, 1994: 3). For Liverpool, with its militant (antiprogressive/post-Fordist attitudes) past (see Frost and North, 2013), this transformation is significant. The transformation is notable as it exhibits the 'weakening of older collective solidarities ... [with an] emergence of new identities associated with greater work flexibility' (Hall, 1988, cited in Amin, 1994: 4) to entice investment, and with it a depoliticised inhabitant (MacLeod, 2011).

By moving away from 'mass-production', the interpretation of citizenship is transformed, as the inhabitants are prompted towards a neoliberal agenda of flexibility, rather than the stability of the past. Such an ideology 'rests on the belief that open, competitive and unregulated markets, liberated from state interference and the actions of social collectives, represent the optimal mechanism for socioeconomic development' (Peck et al., 2009: 50). Distancing from 'mass-production' is indicated through the diversification in 'people and processes' found at the manufacturing plant. The fact that the type of car manufactured is 'award winning' also becomes attributed to the workforce that were given the training to become 'award winning', as such an amount of time and investment in them was worthwhile. The high quality of the workforce becomes affiliated with the elegance and comfort of the Jaguar X-TYPE, and the new, post-Fordist way of working.

Once again, what has been detected is that certain characteristics of the workers' abilities are incorporated with the inhabitants' identity, either already in existence or recently acquired, and declared important for the city's (and the 'city region's') regeneration. The two extracts discussed emphasise a very different way of recognising the workforce - the first quotation demonstrates how excessive the inhabitants' talents are, whilst the second focuses on the workforce gaining new talents. What both extracts have in common however is a focus on change - either through talents being 'harnessed' or through 'a million hour training programme'. With such skills being available in the city, because of the inhabitants' credentials, they are given a greater consideration in the regeneration process as they take a role in the new economic opportunities.

\section{The inhabitants' diversity}

While on the one hand the inhabitants of Liverpool are depicted as a one-dimensional, friendly stereotype appropriated to assist in the city's regeneration, on the other hand they are lauded, in a somewhat contradictory manner, for their diversity.

The need for diversity can be found in the Regional Economic Strategy, where it explains how 'We recognise the diversity of the Northwest's people and communities as a real economic asset and we seek to deliver the opportunity of economic participation for all' (North West Development Agency (NWDA), 2006: 3). While the North West encompasses more than just Liverpool, other documents at a more local level also address the importance of diversity (see the proceeding discussion). In the case of this extract, we can see how the local community is re-defined for economic development by an appeal to 'national values ... [and] It is precisely this appeal that is used in legitimating the value of belonging to the particular locality' (Cox 
and Mair, 1988: 317). This image of a diverse community is legitimated and 'made safe' on account of it being well known - it is 'recognisable' and therefore transferable to be exploited for economic gain; it can regenerate a city. In fact, the 'region's diversity' is discussed as 'rich culture' which 'provides an excellent base for engagement with and capitalisation on our distinctive culture' (Action for Sustainability, 2000: 43, emphasis added).

Diversity is beneficial, understood in terms of value and thereby commodified. While in many cities 'diversity' causes tension (see Jones and Wilks-Heeg, 2004), tension is here removed by separating out 'people' and 'communities', as different individuals are recognised and not only seen as a group with shared characteristics (community). This inclusive construction becomes a means of ensuring that everyone (however diverse) can engage in 'economic participation' as it is available 'for all' - no exclusions. Boyle (1997: 1983) explains how '... civic boosterism propagates solutions that legitimate the principles of capitalism and free competition for investment'. By appealing to the local inhabitants, the NWDA not only involves them in such principles, but also infers (see 'hope' as discussed by Anderson and Holden, 2008) that following such principles will create 'economic participation'. As such, this 'civic boosterism' provides what Snow and Benford (1988) describe as a means of feeling involved, and thus 'motivated' to support the regeneration approach. Once again, motivation for further development is obtained by discussing natural aspects of the population (its 'diversity') as valuable and necessary for economic development.

Involving the inhabitants to justify bidding for ECoC08 is evident from the proposal stage. Under the 'World in One City' heading (the original ECoC08 bid strapline), the document explains how 'The City's decision to bid for European Capital of Culture in 2008 reflects Liverpool's cultural wealth and diversity' (Liverpool City Council, 2003: 11). This extract illustrates how the city is anthropomorphised, as its 'cultural wealth and diversity' are later justified in terms of the inhabitants. Leach (2005: 308) argues that '[a]s individuals identify with an environment, so their identity comes to be constituted through that environment'. By combining the representation of the city and its inhabitants (see also Brown and Campelo Santana, 2014), the diversity of the people, and the city's environment produce an inclusive sense of belonging and hope from bidding for ECoC08. Whereas Kavaratzis and Ashworth (2015) state that the locality and the people are utilised in place branding initiatives to persuade the locals, what we can see here is that inclusivity encourages support, and is also opportune.

Declaring shared identity as a reason for deciding to bid for ECoC08 legitimates it for the public. Emphasising a purpose to 'cultural wealth and diversity' suggests that this is what had given the 'City' an impetus and determination to bid. It implies that bidding had to be done for the inhabitants, rather than out of a need for cities to behave competitively (Harvey, 1989) and bid for opportunities to gain investment through large-scale events (Griffiths, 2006). In this instance the 'City' is given strength in its decision to bid for ECoC08, as the 'cultural wealth and diversity' available is due to the inhabitants. They are also, to a certain extent, deemed powerful, as apparently they can influence how the city regenerates. The 'diversity', which gave the city its 'creative wealth', was directed by them. Although how the overall regeneration 
direction taken in Liverpool will manage to meet the demands of such a diverse population is not revealed.

Both extracts discussed have utilised 'diversity' as a means to involve all in Liverpool's regeneration; however, they differ with respect to how this is done. In the NWDA extract, diversity is understood in terms of how it can be manipulated for economic regeneration. On the other hand, the Liverpool City Council quotation attempts to garner support for the bidding process by attributing the impetus in bidding for ECoC08 to the city's (and hence inhabitants') 'cultural wealth and diversity'. Once again it was the 'natural' talent of the inhabitants that was appealed to.

\section{Conclusion}

This article reveals how motivational framing (Snow and Benford, 1988) can be utilised to demonstrate not only how the inhabitants are assimilated into neoliberalism, but also the process by which it is legitimised. Using Liverpool as a case study, it has focused on the appropriation of the inhabitants, to motivate support (Snow and Benford, 1988) for a neoliberal agenda. Historical narratives are employed to persuade future direction. Natural characteristics are utilised for following a neoliberal agenda, particularly as it will give the inhabitants an opportunity to reap the economic benefits. This approach of utilising the inhabitants' characteristics legitimates the focus on neoliberalism. It constructs the impression that they are included within the regeneration initiatives pursued, which subsequently can be deployed to signify democratic involvement. Similarly, the inhabitants' shared values, which are appealed to, reveal that they are already conforming to a neoliberal agenda. The opportunities described from being involved mean it would be irresponsible not to participate.

By having well-managed and exploitable intangible characteristics the inhabitants become a unique selling point for a competitive advantage. Portrayal of the inhabitants not only appropriates what is regarded as 'good' behaviour for successful urban regeneration, but also ensures that only those who improve their behaviour can be involved. Improvement entails performing a safe stereotypical image for an opportunity to share in the sense of belonging provided through urban regeneration initiatives. Persuasion, through appealing to a well known, albeit historical image, which focuses on the intangible, has an impact: stereotypes are emphasised, at the expense of moving forward.

If the inhabitants wish to capitalise on the changes, by behaving appropriately: living up to the stereotypes, they can be a part of what the Liverpool City Region Development Programme Report 2006 describes as follows:

There is now an air of renewed optimism emanating from across the City Region and The Mersey Partnership and its partners are committed through this strategy in delivering the vibrant and competitive economy the people of our City Region deserve. (The Mersey Partnership, 2006: 2) 
Control over how urban regeneration initiatives are pursued in Liverpool during ECoC08 therefore corresponds to Furbey's (1999: 434) argument that 'the "location" of current urban regeneration continues to be within the powerful context of state and commercial concerns to achieve global competitiveness'. Understanding the real complexity of place and the identity of its inhabitants is deficient in such regeneration initiatives. Thus, it can be argued that local and regional government has been symbolic in its involvement of communities, through appropriating their characteristics to give the perception of influence (see also Eshuis and Edwards, 2013). By incorporating the inhabitants in this manner, their involvement in urban regeneration strategies can be questioned as it demonstrates a lack of partnership or engagement with local communities (Couch, 2003). Issues recognised by Couch in 2003 remain significant in 2017 (Zenker et al., 2017) and such a lack of dialogue with the inhabitants illustrates how the problems found in communities are not being addressed, as rather, the conviction presented in the narratives is that all is satisfactory (Schaller et al., 2002). Focusing on clichés and typecasting only presents an image of the inhabitants, instead of understanding conflicting identities that are found in deindustrialised cities (Nayak, 2006). Improving a city will be a much greater challenge for its inhabitants than what policy makers are inclined to illustrate. Consequently, the current motivational incentive that it will be 'easy' needs to be revised.

Declaration of conflicting interests:

The author(s) declared no potential conflicts of interest with respect to the research, authorship, and/or publication of this article.

Funding

The author(s) received no financial support for the research, authorship, and/or publication of this article.

\section{Notes}

1.

The eight 'core cities' in the ODPM 2004 report were: Birmingham, Bristol, Leeds, Liverpool, Manchester, Newcastle Gateshead, Nottingham and Sheffield.

2.

The tier, or tiers (in England) by which the council or local government is controlled (www.hmrc.gov.uk).

3.

Set up in 1985 by the European Union, the annual title of City of Culture focused on celebrating the high arts. By 1990 when Glasgow held the event, the city used its status for regeneration purposes. In 1999 the title changed to European Capital of Culture (Gold and Gold, 2005).

4.

Gilman and Burn's (1982) analysis of Liverpool's docklands describes how from the 1960s, a 
change in international trading links impacted heavily on Liverpool. The change from handling products in bulk towards container shipping affected the physical size and facilities required in a port. Liverpool developed a new dockland complex in Seaforth and Garston that could operate container berths as it was based in deep water. These new docklands employed fewer staff and led to the old warehouses and docklands in the centre of Liverpool becoming derelict.

5.

The Culture Company was initially set up in 2000 as a private company with the aim of coordinating the bid for Liverpool to be nominated ECoC08. Members of Liverpool City Council were seconded to the limited company, while other members of staff were appointed from other organisations.

6.

Liverpool Vision was one of the first such Urban Regeneration Companies piloted by Central Government in 1999, with Manchester and Sheffield, in advance of the model being driven out to another 12 cities in 2004.

7.

Established in 1993 as a partnership between LAs in the North West, The Mersey Partnership had responsibility for marketing Liverpool and Merseyside for business and tourism investment, and coordinating economic development.

8.

The North West Development Agency was established in 1998, funded by central government, with responsibility for business development and regeneration in the region. All regional development agencies were abolished in 2012 (see www.nao.org.uk and www.gov.uk).

9.

Halewood is a town in Merseyside, about eight miles from Liverpool. In the 1930s, because of overcrowding in Liverpool, new housing was built by Liverpool Corporation in Halewood, with further housing estates built between 1950 and 1970. Halewood had problems of high unemployment until 1960 when the Ford Motor Company opened a car factory in the area (http://history.knowsley.gov.uk/information/print_text.msql?name=Halewood\&ref=hworigin s). 